\title{
TIPOS DE SUBSTRATOS PARA GERMINAÇÃO DE SEMENTES DE PALMEIRA- REAL-AUSTRALIANA (Archontophoenix alexandrae H. WENDL. \& DRUDE) ${ }^{1}$
}

\author{
Cibele Chalita Martins², Isliana Griebler Ribeiro Caldas³ ${ }^{3}$ Carla Gomes Machado ${ }^{4}$ e Wilson de Souza \\ Dourado $^{5}$
}

\begin{abstract}
RESUMO - Os objetivos deste trabalho foram avaliar o desempenho germinativo de sementes de palmeiraaustraliana em diferentes substratos e estabelecer a granulometria e intensidade de umedecimento adequado. A semeadura foi realizada com quatro repetições de 25 sementes em solo, areia, rolo de papel e em vermiculita de diferentes granulometrias: mícron $(0,15-0,20 \mathrm{~mm})$, superfina $(0,21-0,30 \mathrm{~mm})$, fina $(0,30-0,50 \mathrm{~mm})$ e média (1,19-0,50 mm), umedecidas com 0,$5 ; 1,0 ; 1,5$; e 2,0 vezes o seu peso em água. O teste de germinação foi conduzido a $20-30^{\circ} \mathrm{C}$, avaliando-se a primeira contagem do teste aos sete dias após a semeadura e, semanalmente, a germinação (plântulas normais) até os 35 dias, quando foram contabilizadas, também, as plântulas anormais e as sementes mortas. Calcularam-se o tempo médio e frequência relativa de germinação. A vermiculita mícron umedecida com uma vez o seu peso em água apresentou o melhor desempenho como substrato para o teste de germinação de sementes de palmeira-real-australiana, por possibilitar a máxima germinação das sementes (90\%) e velocidade de germinação, demandando tempo médio de 15,3 dias nesse processo.
\end{abstract}

Palavras-chave: Umedecimento, Granulometria, Vermiculita, Velocidade de germinação e Archontophoenix alexandrae.

\section{SUBSTRATE TYPES TO KING PALM SEEDS (Archontophoenix alexandrae H. WENDL. \& DRUDE) GERMINATION}

\begin{abstract}
The objective of this work was to evaluate germinative performance of king palm seeds in different substrates and to set appropriate particle size and moisture for this substrate. Sowing was done with for replications of 25 seeds in soil, sand, paper rolls, and vermiculite of different size: micron (0.15-0.20mm), superfine (0.21-0.30mm), fine $(0.30-0.50 \mathrm{~mm})$ and medium $(1.19-0.50 \mathrm{~mm})$ moistened with 0.5, 1.0, 1.5 and 2.0 times its weight in water. Germination test was carried out at $20-30^{\circ} \mathrm{C}$, evaluating the first test count seven days after sowing and germination was evaluated weekly until 35 days, when abnormal seedlings and dead seeds were also counted. Germination average time and relative frequency were calculated. Micron vermiculite moistened with 1.0 times its weight in water presented the best performance as substrate for germination test of king palm seeds because it possibilities maximum germination of seeds (90\%) and germination rate, requiring an average time of 15.3 days in this process.
\end{abstract}

Keywords: Moistening, Particle size, Vermiculite, Germination rate and Archontophoenix alexandrae.

\footnotetext{
${ }^{1}$ Recebido em 10.10.2009 e aceito para publicação em 31.10.2011.

${ }^{2}$ Faculdade de Tecnologia do Estado de São Paulo - Campus de Capão Bonito, FATEC, Brasil. E-mail: $<$ cibele@fca.unesp.br>

${ }^{3}$ Faculdade de Ciências Agronômicas, FCA / Unesp, Brasil. E-mail:<igrcaldas@yahoo.com.br>.

${ }^{4}$ Universidade Estadual de Goiás, UEG, Brasil. E-mail:<carlagomesmachado@gmail.com>.

${ }^{5}$ Faculdade de Ciências Agronômicas, FCA / Unesp, Brasil. E-mail:<wilsondourado2004@yahoo.com.br>.
} 


\section{INTRODUÇÃO}

A palmeira Archontophoenix alexandrae H. Wendl. \& Drude, pertencente à família Arecaceae, é originária da Austrália e foi introduzida no Brasil como planta ornamental. Na última década, essa espécie vem sendo plantada em áreas de produção de palmito, principalmente nas Regiões Sul e Sudeste do Brasil (VALLILO et al., 2004; CHARLO et al., 2006).

A palmeira-real australiana é propagada exclusivamente por meio de sementes, as quais são classificadas como recalcitrantes, não podendo ser armazenadas em temperaturas baixas, e perdem a viabilidade se desidratadas em teores de água inferiores a 15\% (MARTINS et al., 2003). Os procedimentos para a germinação da palmeira-real-australiana, assim como da quase totalidade das espécies florestais, ainda não estão padronizados pelas Regras para Análise de Sementes - RAS (BRASIL, 2009), publicação que normatiza a metodologia desse teste quanto às recomendações de temperaturas, tipos e intensidade de umedecimento dos substratos, critérios de avaliação, entre outras. Essas recomendações visam oferecer condições supostamente ideais ao teste para estimar o potencial máximo de germinação de um lote.

A vermiculita é um tipo de substrato comumente utilizado para a produção de mudas de espécies florestais e também poderia ser utilizada nos Laboratórios de Análise de Sementes como substrato para o teste-padrão de germinação, por apresentar vantagens, como: fácil obtenção, viabilidade econômica, uniformidade na composição química e granulométrica, porosidade, capacidade de retenção de água e baixa densidade (FIGLIOLIA et al., 1993; MARTINS et al., 2009). Adicionalmente, é um produto industrializado e estéril, obtido a partir do processo de expansão da mica, que é realizada entre 800 e $900^{\circ} \mathrm{C}$ (EUCATEX, 2009). Quanto à granulometria do material, existem para comercialização quatro tipos de vermiculita: mícron (90 a 100\% das partículas entre 0,15-0,20 mm), superfina (95 a 100\% das partículas entre 0,21 e 0,30 mm), fina (90 a 100\% das partículas entre 0,30 e 0,50 mm) e média (90 a 100\% das partículas entre 1,19-0,50 mm). Não obstante, não há referências a esse substrato nas RAS, somente para o uso de papel, solo e areia para serem utilizados nos testes (BRASIL, 2009).

As Regras para Análise de Sementes estabelecem para o teste-padrão de germinação em papel a adição do volume de água equivalente a duas até três vezes o peso do substrato. No caso do uso de substrato de areia ou solo, é recomendado o umedecimento com até $50 \%$ e $60 \%$ da capacidade de retenção do substrato em água, para sementes de cereais e de Fabaceae, respectivamente.

O umedecimento deve ocorrer em níveis de água adequados ao tipo de substrato a ser utilizado, pois materiais diferentes possuem características próprias de porosidade, estrutura, agregação, superfície de contato com a semente e capacidade de retenção de água. Não havendo disponibilidade hídrica suficiente, o processo de germinação pode ser seriamente prejudicado, levando o embrião à morte (MARCOS FILHO, 2005). Da mesma forma, o excesso de água no substrato também prejudica o processo germinativo, devido à menor aeração (MARCOS FILHO, 2005). Esses fatos são comprovados por trabalhos sobre o umedecimento do substrato durante o teste de germinação, realizado com sementes de diversas espécies, florestais e agrícolas (TOLEDO; PEDREIRA, 1984; VARELAetal., 2005; RAMOS et al., 2006; MARTINS et al., 2009).

Em sementes de A. alexandrae, Charlo et al. (2006) verificaram que a utilização de Plantmax ${ }^{\circledR}$ como substrato para a produção de mudas em viveiro promoveu maior desenvolvimento das raízes e emergência das plântulas do que o uso do substrato areia com terra e as misturas de proporções iguais de terra, areia e esterco; esses autores consideraram que as condições mais adequadas para a germinação dessas sementes estariam relacionadas com a umidade e aeração dos substratos. Pivetta et al. (2008) verificaram que a vermiculita foi o substrato mais adequado para a germinação de Archontophoenix cunninghamii H. Wendl. \& Drude, em comparação com areia e esfagno. As Regras de Análise de Sementes (BRASIL, 2009) estabelecem para sementes de Euterpe edulis o uso da areia como substrato para o testepadrão de germinação.

Os objetivos deste trabalho foram avaliar o desempenho germinativo de sementes de palmeiraaustraliana em diferentes substratos e estabelecer a granulometria e intensidade de umedecimento adequado.

\section{MATERIAL E MÉTODOS}

Frutos de A. alexandrae, com coloração do epicarpo vermelho-brilhante e em estádio inicial de dispersão (BOVI, 1998), foram coletados manualmente 
em 15 indivíduos, em 17 de setembro de 2007, na Fazenda Experimental Lageado (UNESP), em Botucatu, SP, e transportados em embalagem de polietileno (20 ìm de espessura) até o Laboratório de Análise de Sementes do Departamento de Produção Vegetal da Faculdade de Ciências Agronômicas da UNESP, onde foram despolpados. No dia seguinte à colheita, os frutos foram submetidos ao beneficiamento para a remoção da polpa, mediante a fricção em peneira com malha de aço e lavagem em água corrente para a retirada do excesso de resíduos (CHARLOT et al., 2006).

As sementes que apresentavam malformação, danificadas ou estavam abaixo do peso médio estabelecido para a realização do experimento (0,69 g) foram eliminadas. O teor de água das sementes foi determinado pelo método da estufa a $105 \pm 3{ }^{\circ} \mathrm{C}$ por 24 h (BRASIL, 2009), utilizando-se quatro repetições de 10 sementes cada. No período de tempo decorrido entre a colheita, o despolpamento e a instalação dos testes de avaliação de qualidade (quatro dias), as sementes foram acondicionadas em sacos de polietileno e armazenadas a $15^{\circ} \mathrm{C}$, para a manutenção da qualidade fisiológica (MARTINS et al., 2003).

Foram avaliados os seguintes substratos: rolo de papel, entre solo (partículas entre 0,062 e 0,031 mm), entre areia (partículas entre 0,50-0 e $25 \mathrm{~mm}$ ) e entre vermiculita mícron, superfina, fina e média (partículas entre 0,15 e 0,20 mm; 0,21 e 0,30 mm; 0,30 e 0,50 mm e 1,19-0,50 mm, respectivamente).

O umedecimento dos substratos areia e solo foi realizado com, respectivamente, $60 \%$ e $50 \%$ da capacidade de campo em água e o do papel, com 2,5 vezes o peso do substrato em água (BRASIL, 2009). Esses substratos com respectivas condições de umedecimento foram considerados tratamentos-testemunha.

O substrato vermiculita foi umedecido com 0,5 ; 1,$0 ; 1,5$; e 2,0 vezes o seu peso em água. Não houve reumedecimento dos substratos no decorrer do experimento. Para que a distância entre as sementes em todos os tipos de substratos fosse igual, a germinação em areia, solo e vermiculita foi conduzida em caixas plásticas de $30,2 \mathrm{~cm}$ x 20,8 cm x 6,3 cm, por ser similar, em comprimento e largura, às dimensões do papel e, com exceção deste último substrato, as sementes foram semeadas a $5 \mathrm{~mm}$ de profundidade. Nas câmaras de germinação, após a instalação do teste os rolos de papel e as caixas plásticas com substrato permaneceram acondicionados dentro de sacos plásticos de 0,033 mm de espessura fechados, para evitar a desidratação (COIMBRA et al., 2007).

O efeito do substrato sobre o desempenho germinativo das sementes foi avaliado pelo teste de germinação e de primeira contagem na temperatura alternada de $20-30{ }^{\circ} \mathrm{C}$. A avaliação do teste de primeira contagem foi realizada sete dias após a semeadura, contabilizando-se a porcentagem de plântulas normais e seguindo os critérios de avaliação de plântulas adotados por Charlo et al. (2006). A partir dessa data, a contagem de plântulas normais foi realizada semanalmente até que a germinação cessasse (35 dias), quando foram calculadas as porcentagens de germinação (plântulas normais), plântulas anormais e sementes mortas.

No procedimento estatístico, a análise de variância de cada teste foi realizada separadamente, com delineamento inteiramente casualizado com quatro repetições. As médias foram comparadas pelo teste de Tukey a 5\% de probabilidade. Antes das análises, os dados de primeira contagem, germinação e plântulas anormais foram transformados em arcosseno $(\mathrm{x}+1) /$ $100) 1 / 2$ e os de sementes mortas, em arcosseno $(\mathrm{x} / 100)^{1 / 2}$ (BANZATTO; KRONKA, 2006). As médias apresentadas nas tabelas são de dados não transformados. A partir da porcentagem de sementes germinadas, foram calculados o tempo médio e a frequência relativa de germinação (SANTANA; RANAL, 2004).

\section{RESULTADOS}

As sementes utilizadas no teste de germinação apresentaram o teor de água de 47,4\%. A semeadura em vermiculita mícron umedecida com água uma vez o seu peso apresentou resultado de germinação significativamente superior ao dos substratos solo, areia e papel (testemunhas), embora não tenha diferido dos valores obtidos em vermiculita mícron, super fina, fina e média umedecidas com 1,5 e 2,0 vezes o seu peso em água (Tabela 1). Quanto à velocidade de germinação, avaliada pelo teste da primeira contagem, esses últimos tratamentos, juntamente com a semeadura em solo, em vermiculita mícron, super fina e média umedecidas com uma vez o seu peso em água, foram, também, os tratamentos mais favoráveis.

Revista Árvore, Viçosa-MG, v.35, n.6, p.1189-1196, 2011 
Tabela 1 - Efeito do tipo de substrato sobre o desempenho germinativo de sementes de palmeira-real-australiana. Table 1-Substrate types effect on the germination performance of king palm seeds.

\begin{tabular}{|c|c|c|c|c|c|}
\hline Substrato & $\begin{array}{c}\text { Umedecimento } \\
\text { do substrato }\end{array}$ & $\begin{array}{c}\text { Primeira contagem } \\
(\%)^{1}\end{array}$ & $\begin{array}{c}\text { Germinação } \\
(\%)^{1} \\
\end{array}$ & $\begin{array}{c}\text { Plântulas Anormais } \\
\qquad(\%)^{1}\end{array}$ & $\begin{array}{c}\text { Sementes Mortas } \\
(\%)^{2}\end{array}$ \\
\hline $\begin{array}{c}\text { SOLO } \\
\text { (testemunha) }\end{array}$ & $60 \%$ сс & 28 abc & 66 bcde & 9 bcd & 25 cdef \\
\hline $\begin{array}{c}\text { AREIA } \\
\text { (testemunha) }\end{array}$ & $50 \%$ сс & $9 \mathrm{~cd}$ & $63 \mathrm{cdef}$ & 7 bcd & 30 cdef \\
\hline $\begin{array}{c}\text { PAPEL } \\
\text { (testemunha) }\end{array}$ & $2,0 x$ & $0 \mathrm{~d}$ & 62 def & 15 abc & 23 def \\
\hline MI & $\begin{array}{l}0,5 \mathrm{x} \\
1,0 \mathrm{x} \\
1,5 \mathrm{x} \\
2,0 \mathrm{x}\end{array}$ & $\begin{array}{c}11 \text { bcd } \\
34 \text { ab } \\
25 \text { abc } \\
21 \text { abc }\end{array}$ & $\begin{array}{c}42 \text { efg } \\
90 \text { a } \\
83 \text { abc } \\
74 \text { abcd }\end{array}$ & $\begin{array}{c}16 \mathrm{abc} \\
4 \mathrm{~cd} \\
5 \mathrm{~cd} \\
2 \mathrm{~cd}\end{array}$ & $\begin{array}{c}42 \mathrm{bc} \\
6 \mathrm{~g} \\
12 \mathrm{fg} \\
24 \mathrm{cdef}\end{array}$ \\
\hline SF & $\begin{array}{l}0,5 \mathrm{x} \\
1,0 \mathrm{x} \\
1,5 \mathrm{x} \\
2,0 \mathrm{x}\end{array}$ & $\begin{array}{c}0 \mathrm{~d} \\
15 \mathrm{abcd} \\
33 \mathrm{ab} \\
39 \mathrm{a}\end{array}$ & $\begin{array}{c}2 \mathrm{i} \\
28 \mathrm{gh} \\
84 \mathrm{ab} \\
86 \mathrm{ab}\end{array}$ & $\begin{array}{c}13 \mathrm{abcd} \\
26 \mathrm{ab} \\
4 \mathrm{~cd} \\
2 \mathrm{~cd}\end{array}$ & $\begin{array}{c}85 \mathrm{a} \\
46 \mathrm{bc} \\
12 \mathrm{fg} \\
12 \mathrm{efg}\end{array}$ \\
\hline $\mathrm{F}$ & $\begin{array}{l}0,5 \mathrm{x} \\
1,0 \mathrm{x} \\
1,5 \mathrm{x} \\
2,0 \mathrm{x}\end{array}$ & $\begin{array}{c}0 \mathrm{~d} \\
11 \mathrm{bcd} \\
34 \mathrm{ab} \\
28 \mathrm{abc}\end{array}$ & $\begin{array}{c}0 \mathrm{i} \\
17 \mathrm{~h} \\
77 \mathrm{abcd} \\
86 \mathrm{ab}\end{array}$ & $\begin{array}{c}6 \text { bcd } \\
23 \mathrm{ab} \\
7 \text { bcd } \\
0 \mathrm{~d}\end{array}$ & $\begin{array}{c}94 \mathrm{a} \\
60 \mathrm{~b} \\
16 \mathrm{efg} \\
14 \mathrm{efg}\end{array}$ \\
\hline $\bar{M}$ & $\begin{array}{l}0,5 \mathrm{x} \\
1,0 \mathrm{x} \\
1,5 \mathrm{x} \\
2,0 \mathrm{x}\end{array}$ & $\begin{array}{c}11 \text { bcd } \\
18 \text { abc } \\
35 \mathrm{ab} \\
29 \mathrm{abc}\end{array}$ & $\begin{array}{c}40 \text { fg } \\
66 \text { bcde } \\
73 \text { abcd } \\
75 \text { abcd }\end{array}$ & $\begin{array}{c}29 \text { a } \\
11 \text { abcd } \\
10 \text { bcd } \\
8 \text { abcd }\end{array}$ & $\begin{array}{l}31 \text { cde } \\
23 \text { def } \\
17 \text { efg } \\
17 \text { efg }\end{array}$ \\
\hline & CV (\%) & 28,0 & 11,0 & 35,2 & 15,9 \\
\hline
\end{tabular}

Em cada característica avaliada, médias seguidas pela mesma letra na coluna não diferem estatisticamente entre si, pelo teste de Tukey $(\mathrm{p}<0,05)$. As médias apresentadas são dos dados originais. ${ }^{1} \mathrm{O}$ s dados foram transformados em arcosseno $((\mathrm{x}+1) / 100)^{1 / 2} \cdot{ }^{2}$ Os dados foram transformados em arcosseno $(\mathrm{x} / 100)^{1 / 2}$.

$\mathrm{Cc}=$ capacidade de campo, $\mathrm{x}=$ vez o peso do substrato em água.

Nas Figuras 1 e 2 estão apresentados os resultados do tempo médio de germinação das sementes no substrato vermiculita mícron umedecida com uma vez o seu peso, que foi de 15,3 dias, maior que o tempo apresentado para a vermiculita super fina e média, umedecidas com 1,5 e 2,0 vezes o seu peso, entre 14,7 e 12,9 dias. Esses tratamentos apresentaram porcentagem de germinação estatisticamente similar ao primeiro. Esses tratamentos mostraram máxima frequência relativa da geminação entre 7 e 14 dias.

As condições de substrato mais prejudiciais à velocidade de germinação foram verificadas em substrato rolo de papel e vermiculita fina ou super fina umedecidos com uma vez o seu peso, pois resultaram em valores nulos no teste da primeira contagem e, com exceção do rolo de papel, também apresentaram as mais baixas porcentagens de germinação e maior ocorrência de sementes mortas (Tabela 1).
No caso do substrato papel e da vermiculita de qualquer granulometria umedecida com 0,5 vez o seu peso em água, verificou-se que o meio foi desfavorável ao processo germinativo, observando maior porcentagem de plântulas anormais ou de sementes mortas nesses tratamentos.

\section{DISCUSSÃO}

Os cuidados adotados no acondicionamento e armazenamento dos frutos e sementes entre a colheita e a instalação dos testes permitiram a manutenção do teor de água da semente em 47,4\%, similar ao valor de $47,7 \%$ obtido na mesma espécie por Vallilo et al. (2004). O uso da vermiculita mícron umedecida com uma vez o seu peso apresentou bom desempenho como substrato no teste de germinação de sementes de palmeira-real-australiana, por possibilitar a porcentagem de germinação das sementes (90\%) superior à dos 

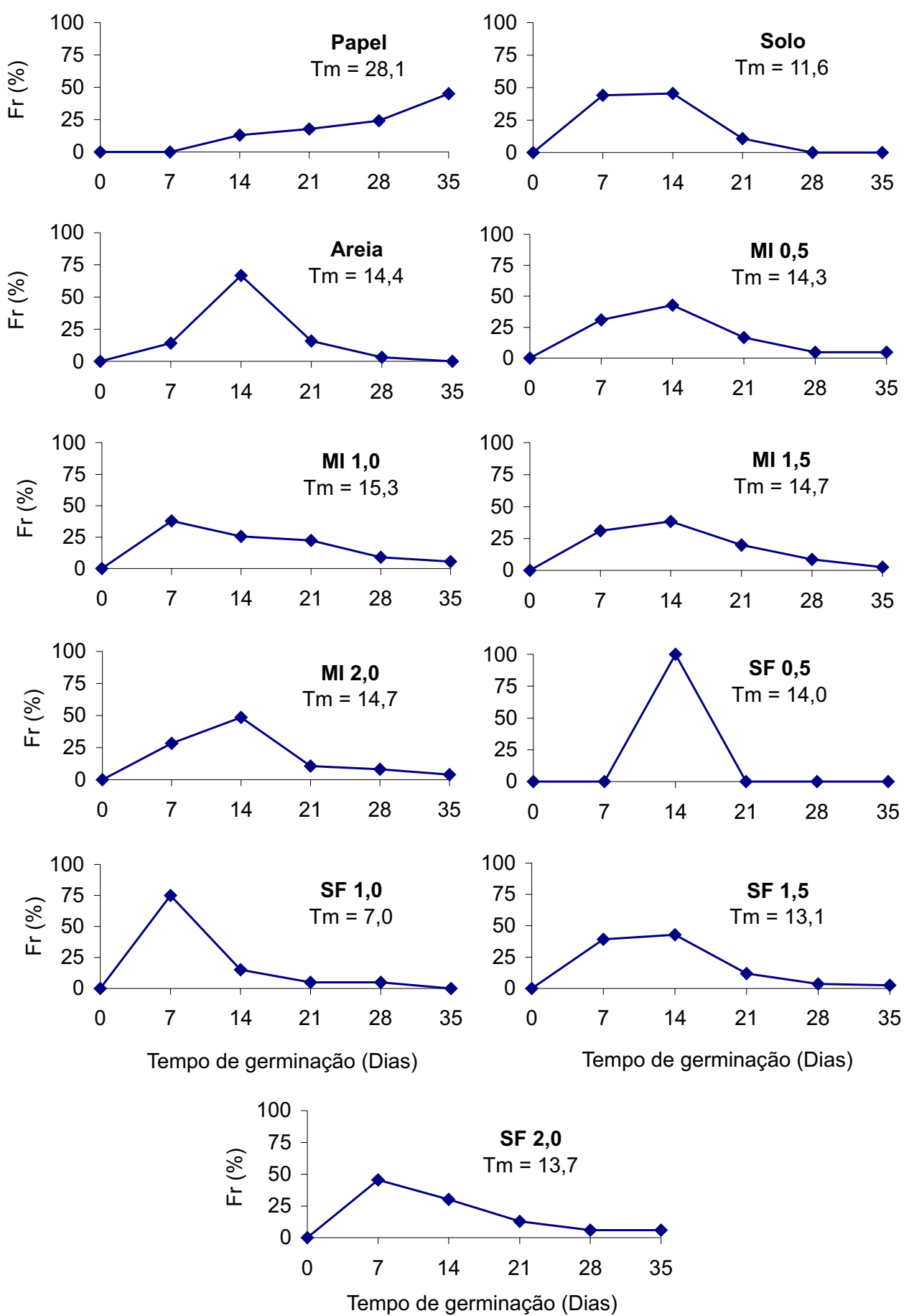

Figura 1 - Frequência relativa (Fr) e tempo médio (Tm) da germinação de sementes de palmeira-real-australiana em rolo de papel, solo, areia, vermiculita mícron (MI) e superfina (SF) umedecidos com 0,$5 ; 1,0 ; 1,5$; e 2,0 vezes o seu peso em água.

Figure 1 - Relative frequency $(\mathrm{Fr})$ and averagetime $(\mathrm{Tm})$ of germination of king palm seeds in paper, soil, sand, micron vermiculite (MI) and super fine vermiculite (SF) moistened with 0.5, 1.0, 1, 5 and 2.0 times its weight in water. 

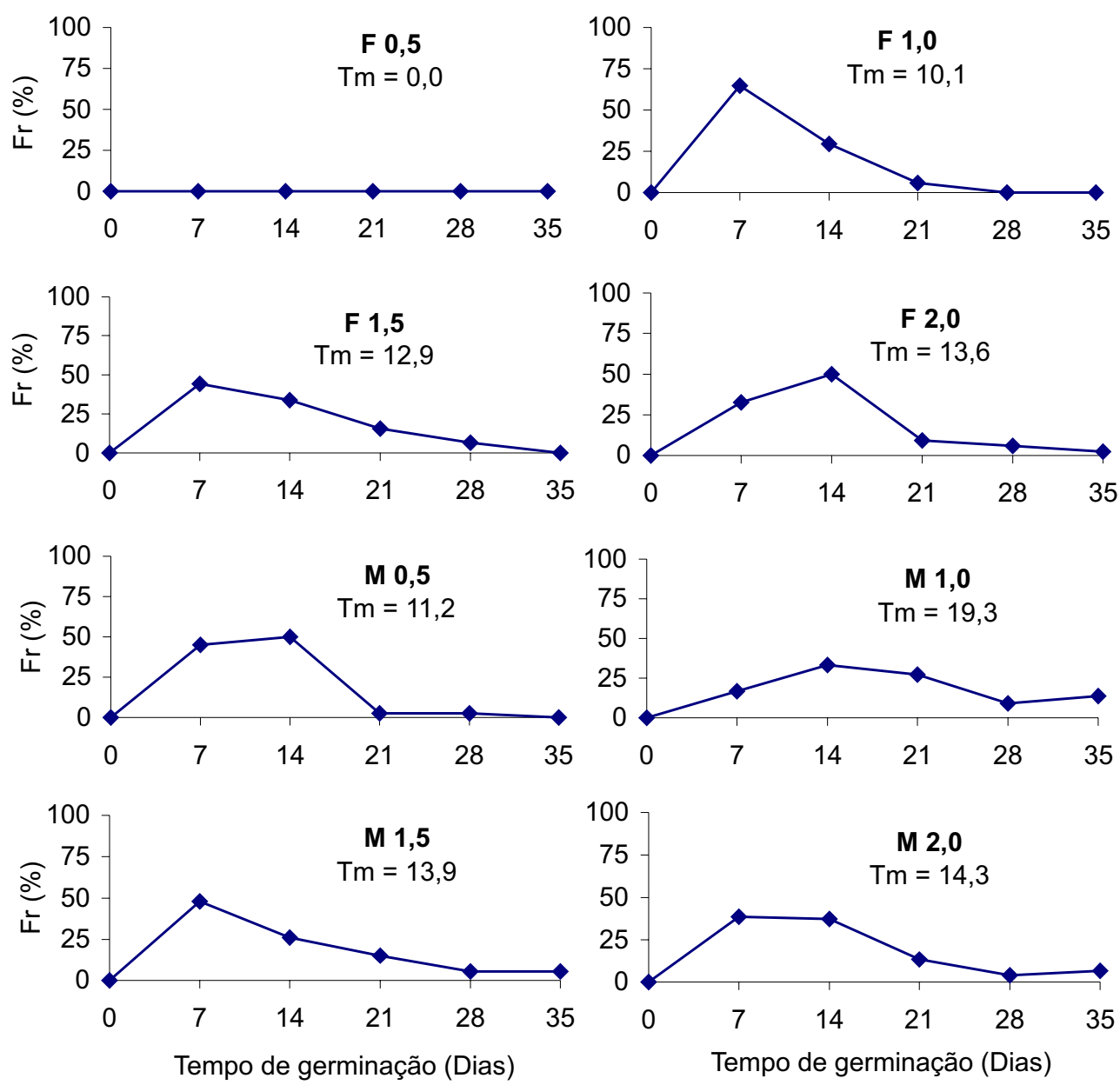

Figura 2 - Frequência relativa (Fr) e tempo médio (Tm) da germinação de sementes de palmeira-real-australiana em vermiculita fina (F) e média (M) umedecidas com 0,$5 ; 1,0 ; 1,5$; e 2,0 vezes o seu peso em água.

Figure 2 - Relative frequency (Fr) and average time (Tm) of germination of king palm seeds in paper, soil, sand, fine (MI) and medium vermiculite (M) moistened with 0.5, 1.0, 1, 5 and 2.0 times its weight in water.

substratos rolo de papel, solo e areia, que foram os tratamentos-testemunha deste trabalho e permitiram uma velocidade de germinação similar à dos tratamentos mais favoráveis (vermiculita micron, super fina, fina e média umedecidas com 1,5 e 2,0 vezes o seu peso em água), demandando tempo médio de germinação de 15,3 dias (Tabela 1 e Figuras 1 e 2). Pivetta et al. (2008) verificaram que a vermiculita foi o substrato mais adequado do que a areia para a germinação de Archontophoenix cunninghamii H. Wendl. \& Drude.

O efeito prejudicial à velocidade de germinação com o uso do substrato de papel, vermiculita fina e superfina umedecidos com uma vez o seu peso, permite inferir que para sementes de palmeira- real-australiana o teor de água relativamente alto da semente $(47,4 \%)$ não foi suficiente para desencadear as atividades metabólicas do processo germinativo, havendo, portanto, a necessidade de suprimento de água adicional do substrato, embora este suprimento seja proporcionalmente menor em sementes recalcitrantes do que o que seria exigido para sementes ortodoxas (TOLEDO; PEDREIRA, 1984; BRASIL, 1992; VARELA et al., 2005; RAMOS et al., 2006; MARTINS et al., 2009), que apresentaram teor de água entre 8 e $13 \%$ por ocasião da semeadura.

No caso dos substratos papel e vermiculita de qualquer granulometria umedecidos com 0,5 vez o seu peso em água, verificou-se que o meio foi desfavorável

Revista Árvore, Viçosa-MG, v.35, n.6, p.1189-1196, 2011 
ao processo germinativo, observando maior porcentagem de plântulas anormais, senão de sementes mortas nesses tratamentos. Tais dados corroboram os relatos de Marcos Filho (2005) sobre lesões nas plântulas e morte do embrião em condições de baixa disponibilidade hídrica durante a germinação.

A germinação mais lenta verificada na semeadura em papel pode ter ocorrido devido à menor superfície de contato entre a semente de forma ovoide da palmeirareal- australiana e o substrato, em comparação com a semeadura entre solo, areia ou vermiculita (Figuras 1 e 2). A superfície de contato entre a semente e o substrato é um dos fatores que afetam a absorção de água pela semente durante o processo germinativo (CARVALHO; NAKAGAWA, 2000). De modo similar, talvez seja devido à forma da semente e à sua suscetibilidade aos fungos durante à germinação que as Regras para Análise de Sementes (BRASIL, 2009) recomendam somente o substrato areia para o teste de germinação da palmeira Euterpe edulis Mart.

Conclui-se que a vermiculita micron umedecida com uma vez o seu peso em água pode ser utilizada como substrato para o teste de germinação de sementes de palmeira- real-australiana, por possibilitar a máxima germinação das sementes.

\section{REFERÊNCIAS}

BANZATTO, D. A.; KRONKA, S. N.

Experimentação agrícola. 4.ed. Jaboticabal: FUNEP, 2006. 237p.

BRASIL. Ministério da Agricultura, Pecuária e Abastecimento. Secretaria de Defesa Agropecuária. Regras para análise de sementes. Brasília: 2009. 399p.

BOVI, M. L. A. Cultivo da palmeira real australiana visando à produção de palmito. Campinas: Instituto Agronômico de Campinas, 1998. 26p. (Boletim Técnico, 172).

CARVALHO, N. M.; NAKAGAWA, J.

Sementes: ciência, tecnologia e produção. 4.ed. Jaboticabal: FUNEP, 2000. 588p.

CHARLO, H. C. O. et al. Aspectos morfológicos, germinação e desenvolvimento inicial de plântulas de Archontophoenix alexandrae (F. Mueller) H. Wendl. e Drude (Arecaceae) em diferentes substratos. Revista Árvore, v.30, n.6, p.933-940, 2006.
COIMBRA, R. A. et al. Teste de germinação com acondicionamento dos rolos de papel em sacos plásticos visando a otimização dos resultados.

Revista Brasileira de Sementes, v.29, n.1, p.92-97, 2007.

EUCATEX. Isolantes, condicionadores de solo e substratos. Minério de vermiculita crua concentrada. Disponível em: < $\underline{\text { http:// }}$

www.eucatex.com.br/eucatex/

descricao.asp?B2 $=\& \mathrm{~A} 1=15 \& \mathrm{~A} 2=104>$. Acessado em: 23 de mar. de 2009.

FIGLIOLIA, M. B.; OLIVEIRA, E. C.; PIÑA RODRIGUES, F. C. M. Análise de sementes. In: AGUIAR, I. B.; PIÑA RODRIGUES, F. C. M.; FIGLIOLIA, M. B. (Eds). Sementes florestais tropicais. Brasília: ABRATES, 1993. p.137-174.

MARCOS-FILHO, J. Fisiologia de sementes de plantas cultivadas. Piracicaba: FEALQ, 2005. 495p.

MARTINS, C. C.; BOVI, M. L. A.; NAKAGAWA, J. Desiccation effects on germination and vigor of King palm seeds. Horticultura Brasileira, v.21, n.1, p.88-92, 2003.

MARTINS, C. C.; BOVI, M. L. A.; SPIERING, S. H. Umedecimento do substrato na emergência e vigor de plântulas de pupunheira. Revista Brasileira de Fruticultura, v.31, n.1, p.224-230, 2009.

PIVETTA, K. F. L. et al. Tamanho do diásporo, substrato e temperatura na germinação de sementes de Archontophoenix cuninghamii. Revista de Biologia e Ciências da Terra, v.8, n.1, p. 126-134, 2008.

RAMOS, M. B. P.; VARELA, V. P.; MELO, M. F. F. Influência da temperatura e da quantidade de água no substrato sobre a germinação de sementes de Ochroma pyramidale (Cav. ex Lam.) Urban (pau-debalsa). Acta Amazônica, v.36, n.1, p.103-106, 2006.

SANTANA, D. G.; RANAL, M. A. Análise da germinação: um enfoque estatístico. Brasília: Universidade de Brasília, 2004. 248p.

TOLEDO, F. F.; PEDREIRA, A. A. S. Quantidade de solução de nitrato de potássio e germinação de sementes de capim colonião. Revista Brasileira de Sementes, v.6, n.1, p.61-70, 1984.

Revista Árvore, Viçosa-MG, v.35, n.6, p.1189-1196, 2011 
VALLILO, M. I. et al. Composição química das sementes de Archontophoenix alexandrae H. Wendl. \& Drude (Arecaceae). Revista Árvore, v.28, n.5, p.676-679, 2004.
VARELA, V. P.; RAMOS, M. B. P.; MELO, M. F. F. Umedecimento do substrato e temperatura na germinação de sementes de angelim-pedra (Dinizia excelsa Ducke). Revista Brasileira de Sementes, v.27, n.2, p.130-135, 2005. 